\title{
Endonasal dacryocystorhinostomy (DCR) without flap and stent (A new technique): Our experience in RIMS, Manipur
}

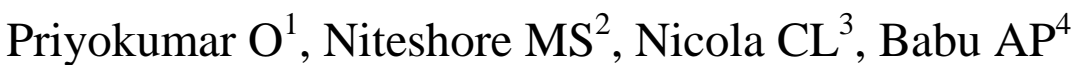 \\ ${ }_{1,2,3,4}$ (Dept. of Otorhinolaryngology, Regional Institute of Medical Sciences, India)
}

\begin{abstract}
Endoscopic dacryocystorhinostomy (DCR) has been the preferred treatment in the management of epiphora and many techniques were described by different authors with different success rates. We describe a new technique of endonasal DCR which has given almost $100 \%$ success rates in the management of nasolacrimal duct obstruction. In this new technique, there is no preparation of lacrimal sac flap nor any stenting is required hence avoids the possible concern of flap survival. It is less costly, technically simpler and easier to perform as it avoids the use of stents and fibrin glue yet simple enough to perform. A prospective study on 13 cases of nasolacrimal duct obstruction (NLDO) was done to see the outcome of management by endoscopic transnasal DCR without stenting. All the cases were diagnosed clinically by regurgitation test, lacrimal syringing and radiologically by CT scan of the nose and paranasal sinuses to confirm the site and cause of obstruction. No major complications were noted intra-operatively or post-operatively. Average followup was 6 months with primary success rate of 100\% irrespective of the etiology. This study is an attempt to justify the safety and effectiveness of endoscopic transnasal DCR without stenting in the management of nasolacrimal duct obstruction.
\end{abstract}

Keyword: dacryocystitis, endonasal dacryocystorhinostomy, nasolacrimal duct obstruction

\section{Introduction}

Dacryocystorhinostomy (DCR) is a surgical procedure performed for the relief of nasolacrimal duct obstruction (NLDO) of either anatomical or functional cause. The first report of DCR (intranasal approach) was by Caldwell in 1893[1]. Later in 1904,Toti described DCR by external approach[2]. Traditionally, DCR is done externally with its potential complications like unwanted external scar and failure of the procedure. The failure is mainly attributed to the closure of the intranasal stoma created by the surgery. McDonough and Meiring described the endoscopic transnasal DCR in 1989. Failure rates with external DCR have been attributed to many factors including position and size of the ostium, common canalicular obstruction, scarring within the anastomosis due to infection or non-absorbable suture material, persistent mucocele, and the sump syndrome. Postoperative soft tissue infections, previous trauma, and silicone tube intubation are other factors that have been attributed to failure. More recently, the frequency of entry into the ethmoidal sinus as opposed to the nose has been highlighted emphasising the importance of adequate knowledge of the nasal anatomy while performing external DCR[3,4,5,6,7,8]. Endoscopic transnasal DCR is a surgical innovation with an attempt to avoid these complications with similar or better results. A preliminary study of 13 cases of endoscopic transnasal DCR without a flap or stenting performed in ORL Department, RIMS, Imphal is presented. The advantages and disadvantages of the procedure are also discussed.

\section{Materials And Methods}

A prospective study was conducted from March 2009 to Sep 2013 in 13 cases with endoscopic transnasal dacryocystorhinostomy (DCR) in the department of Otorhinolaryngology, RIMS, Imphal. All the cases were diagnosed clinically by regurgitation test, lacrimal syringing and confirmed radiologically by CT scan of the nose and paranasal sinuses to ascertain the site and cause of obstruction, thereby excluding the cases of hyperlacrimation. Surgery was done by the same surgeon for all cases. Out of the 13 cases, 12 were primary cases, means no surgical procedures were done before for the same problem while one case was a revision surgery because of failure of the first external DCR done elsewhere. In 6 cases, surgery was done on the right side while the remaining 7 cases were on the left side. Prior to the surgery, routine and specific investigations including CT Scan of the Nose and PNS were done to rule out any causative pathology of NLDO or associated deformity or pathology in nose and paranasal sinuses (PNS) and also to detect any associated anatomical abnormalities or pathological conditions.

All the cases were operated under general anaesthesia. Using a $0^{\circ} 4 \mathrm{~mm}$ nasal endoscope, nasal cavities were packed with ribbon gauze soaked in decongestant solution (5 ampoules of Inj. Adrelanine mixed with 30 $\mathrm{ml}$ of 4\% Lignocaine solution) for a period of about 5-7 minutes. Any anatomical abnormality present was corrected first; setoplasty was done in 7 cases, spurectomy done in 1 case. In 5 cases the anterior ethmoids were removed on the operated side because of the presence of disease. Middle meatal antrostomy (MMA) and 
clearance of disease was done in one patient as the left maxillary sinus had disease. Uncinectomy was done in all the cases after local injections of $2 \%$ Lignocaine with Adrenaline in the strength of 1:20000. Injections were also given over the lateral nasal wall in the vicinity of the nasolacrimal sac area. Two incisions were made, one horizontal from and just above the anterior attachment of middle turbinate extending anteriorly for about $1 \mathrm{~cm}$, another vertical incision was made from the anterior end of the first incision extending downwards towards the superior aspect of inferior turbinate for about $1.5 \mathrm{~cm}$. Mucoperiosteum was elevated from the bone downwards and it was cut inferiorly flush with the inferior turbinate. In all the cases the bone was thick and hard, so, microdrill was used to thin out the bone. Once the bone was thin enough, it was removed using bone punches and back-biting forceps. A generous amount of bone was removed for wide exposure of at least $1 \mathrm{~cm} \mathrm{x} 1 \mathrm{~cm}$ area. Once the bone was removed, the medial wall of the nasolacrimal sac was identified which was confirmed by applying pressure externally over the nasolacrimal sac region. Probing of the lacrimal canalicum was done through the inferior punctum indenting the medial wall of the nasolacrimal sac medially for an easy incision of the wall with a sickle knife. Then, the medial wall was removed completely with a trucut forcep especially in the upper part where the common canaliculus opens into the sac. The main difference in technique is the removal of the medial wall of the nasolacrimal sac without the preparation of a lacrimal sac flap and also the removal of the lateral nasal wall mucosa over the sac and making it flush with the margin of the remaining lacrimal sac. This prevents the exposure of bone and eliminates the possibility of closure of the new lacrimal opening by the displaced flap. Syringing was done through the inferior punctum and the free flow of the saline was established. No stenting was done in all the cases nor was Mitomycin $\mathrm{C}$ used. Light nasal packing was done with ribbon gauze impregnated with antiseptic ointment on the side of surgery which was removed after about 24 hours. The patients were discharged on the next day with antibiotic coverage and saline nasal sprays.

First follow-up was done after 1 week when nasal dressing was done to remove any crust or blood clots. Syringing was also done to check for patency of the tract. Next follow-ups were done on the $2^{\text {nd }}, 4^{\text {th }}$ week post-operative and subsequently after 2, 4, 6 months post-operative. During the follow-ups nasal cavity was inspected and the patency of the tract checked by syringing. In one patient (revision case), there was obstruction of the tear flow with failed syringing because of the presence of fibrosis, synaechia and crusting between the lateral wall and the middle turbinate and crusting during 2 month follow-up. Patient was called to OT and the fibrous tissues and crust were removed establishing the patency of the tract. In the further follow-ups, there was no obstruction in the tear flow.

\section{Results}

Most of the patients in our study were in 20-40 yrs of age, youngest was 7 year old and eldest was 56 years old. Interestingly, 12 of the patients were females and only one male. Right and left sides were equally affected (R6 L7) with no significant preponderance to either side. Bilateral involvement was not seen. The commonest mode of presentation were as shown in TABLE 1.

\section{Figures And Tables}

Table I. Patient Characteristics

\begin{tabular}{|l|l|l|l|}
\hline \multicolumn{1}{|c|}{ Patients } & \multicolumn{1}{|c|}{ Age/Sex } & \multicolumn{1}{|c|}{$\begin{array}{c}\text { Side of } \\
\text { NLDO }\end{array}$} & \multicolumn{1}{|c|}{ Symptoms/History } \\
\hline Patient 1 & $56 \mathrm{yrs} / \mathrm{F}$ & Right & Epiphora, pain and swelling over the sac \\
\hline Patient 2 & $42 \mathrm{yrs} / \mathrm{F}$ & Left & Epiphora \\
\hline Patient 3 & $38 \mathrm{yrs} / \mathrm{F}$ & Right & Epiphora, pus discharge, previous external DCR \\
\hline Patient 4 & $24 \mathrm{yrs} / \mathrm{F}$ & Right & Epiphora, mucopus discharge \\
\hline Patient 5 & $42 \mathrm{yrs} / \mathrm{F}$ & Left & Epiphora and swelling over the sac \\
\hline Patient 6 & $25 \mathrm{yrs} / \mathrm{F}$ & Left & Pain, swelling and mucopus discharge \\
\hline Patient 7 & $7 \mathrm{yrs} / \mathrm{F}$ & Left & Epiphora, swelling and mucous discharge \\
\hline Patient 8 & $36 \mathrm{yrs} / \mathrm{F}$ & Right & Epiphora, swelling, recurrent mucous discharge \\
\hline Patient 9 & $22 \mathrm{yrs} / \mathrm{F}$ & Right & Epiphora, swelling and mucous discharge \\
\hline Patient 10 & $42 \mathrm{yrs} / \mathrm{F}$ & Right & Epiphora, swelling and mucous discharge, recurrent abscess formation \\
& & & \\
\hline Patient 11 & $55 \mathrm{yrs} / \mathrm{F}$ & Left & Epiphora, swelling and mucous discharge, recurrent abscess formation \\
\hline Patient 12 & $22 \mathrm{yrs} / \mathrm{M}$ & Left & Epiphora, pain and swelling over the sac \\
\hline Patient 13 & $23 \mathrm{yrs} / \mathrm{F}$ & Left & Epiphora,mucousdischarge,swelling \\
\hline
\end{tabular}

NLDO - Nasolacrimal duct obstruction, DCR - Dacryocystorhinostomy

Table II. Associated Abnormalities and Surgeries Performed

\begin{tabular}{c|c|c|}
\hline Patients & Other abnormalities & Additionalsurgicalprocedures \\
\hline WWW.1OSrjournals.org & Page
\end{tabular}


Endonasal Dacryocystorhinostomy (Dcr) Without Flap And Stent (A New Technique)...

\begin{tabular}{|l|l|l|}
\hline Patient 1 & DNS (Rt) & Septoplasty \\
\hline Patient 2 & Septal spur (Lt) compressing the IT(Lt) & Spurectomy \\
\hline Patient 3 & $\begin{array}{l}\text { DNS (Rt)compressing upon RtMT with Rt Anterior ethmoid } \\
\text { disease }\end{array}$ & Septoplasty + Anterior FESS (Rt) \\
\hline Patient 4 & DNS (Rt) & Septoplsty \\
\hline Patient 5 & $\begin{array}{l}\text { DNS (Lt), MT hypertrophy (Lt), Ant. Ethmoid disease (Lt), } \\
\text { OMC disease and Max. sinus disease (Lt) }\end{array}$ & $\begin{array}{l}\text { Septoplasty, Anterior Ethmoidectomy, } \\
\text { MMA and maxillary sinus disease clearance }\end{array}$ \\
\hline Patient 6 & DNS (Lt), B/L Concha bullosa of MT, B/L IT hypertrophy, & $\begin{array}{l}\text { Septoplasty, Turbinoplasty of MT (B/L), } \\
\text { Uncinectomy and MMA (Lt) }\end{array}$ \\
\hline Patient 7 & Concha bullosa of Lt. MT & Turbinoplasty Lt. MT \\
\hline Patient 8 & No other significant finding & None \\
\hline Patient 9 & No other significant finding & None \\
\hline Patient 10 & DNS (Rt.), Anterior ethmoid disease(Rt.) & Septoplasty, anterior FESS (Rt) \\
\hline Patient 11 & No other significant finding & None \\
\hline Patient 12 & DNS (Lt), Anterior ethmoid disease(Lt) & Septoplasty, Anterior Ethmoidectomy(Lt) \\
\hline Patient 13 & DNS(Lt), Anterior ethmoid disease(Lt) & Septoplasty, anterior Ethmoidectomy(Lt) \\
\hline
\end{tabular}

DNS - Deviated Nasal Septum, Rt. - Right, Lt. - Left, IT - Inferior Turbinate,

FESS - Functional Endoscopic Sinus Surgery, MT - Middle turbinate, OMC- ostiomeatal complex, MMAMiddle MeatalAntrostomy.

\section{Discussion}

Over the past decade endoscopic DCR has proved itself to be a safe and effective technique for the treatment of lacrimal duct obstruction. Traditionally, DCR is done externally with its potential complications like unwanted external scar and failure of the procedure. The failure is mainly attributed to the closure of the intranasal stoma created by the surgery. The presence of a cutaneous scar, the potential for injury to medial canthal structures, cerebrospinal fluid rhinorrhoea, and functional interference with the physiological action of the lacrimal pump are but a few of the disadvantages of this procedure. Postoperative morbidity including periorbital bruising, epistaxis, and late DCR failure have led to the search for a less invasive approach to the operation[4].

Caldwell in 1893 described the first intranasal DCR[1]. Since then, many variations and modifications in the technique are described by different authors but with each modification the complexity of the surgery increases. With the growth of using endoscopic procedures along with better understanding of the lateral nasal wall anatomy, endonasal DCR became the preferred approach for performing DCR. The development of the endonasal DCR surgery has many advantages over the traditional external approach. however, the endoscopic approach avoids the morbidity of a facial incision. Furthermore, endoscopic techniques have the potential to reduce patient morbidity through improved intraoperative hemostasis, greater utilization of local anesthesia, and shorter hospitalization as compared with conventional techniques.

Many modifications of the original procedure were developed along with the process of development and refinement of the surgery and are reported throughout the world with different success rates. Some of the modifications that were described include various mucosal flap technique, marsupialization, application of mitomycin C, suturing of flaps using fibrin glue, using laser, using powered instruments and microdebrider, with/without uncinectomy, with stents, without stents etc $[9,10,11,12,13,14,15,16,17,18,19]$

As the use of nasal endoscope has greatly increased the surgical field vision, DCR has become safer operation and it became easier to do post-operative assessment of the ostium to ascertain the ostium patency[20]. The minimal invasiveness of the procedure has made the procedure applicable during acute suppurative conditions too [21]. The feasibility of the endonasal approach has been such that even such surgery done under direct vision using laser has been described[ 22].

The use of stents causes granulation formation, adds extra cost and increases patient discomfort[23]. In an attempt to make the surgery simple, affordable and with minimal patient discomfort, we have attempted a new modification which has shown to be very effective and reliable and are described herewith. The success rate has shown to be almost $100 \%$ and even revision cases can be done without much difficulty.

The hallmark of this technique is the removal of the medial wall of the nasolacrimal sac without the formation of a lacrimal sac flap and also the removal of the lateral nasal wall mucosa over the sac and making it flush and apposed with the margin of the remaining lacrimal sac. This prevents the exposure of bone and eliminates the possibility of closing the new lacrimal opening by the displaced flap.

In this new technique, there is no preparation of lacrimal sac flap nor any stenting is required hence avoids the possible concern of flap survival. It is less costly as it avoids the use of stents and fibrin glue yet simple enough even to perform. Other advantages such as avoiding the use of fibrin glue and the feasibility of using this technique in rural setting is another important consideration in this technique.

When closure of the opening is a concern, we believe that the following points are good preventive factors against such complications. 
1. Wide opening of the stoma (approximately $1 \mathrm{~cm}$ )

2. Margin of the cut lacrimal sac is well apposed with the mucosa of the lateral nasal wall hence healing is better.

3. Lesser chances of osteitis as the bones are well covered with the mucosa

4. Less crusting

5. Least chances of flap retraction/ displacement

6. No chance of accidental closure by adhesion in immediate post-operative period as no fibrin glue is used.

Fayers $\mathrm{T}$ et al reported overall functional success of $69 \%$ and anatomical success of $74 \%$ a success rate for external DCR [5].The author's results (100\%) at 6 months and those of others demonstrate a greater than 90\% surgical success rate for patients who undergo primary endoscopic DCR. These results are better than many other endoscopic technique and those described for conventional external DCR techniques. As more otolaryngologists and ophthalmologists become trained in the endoscopic DCR, it is likely that this approach will become the most commonly utilized technique for the treatment of patients who present with epiphora and dacryocystitis from Nasolacrimal duct obstruction.

With the advancement in surgical techniques and better understanding of the nasal anatomy, endonasal DCR has become more refined and the success rates have risen. This affect combined with the advantages of a minimal access surgery and the avoidance of external scar, endonasal DCR is a better surgical option for the treatment of nasolacrimal duct obstruction. This new technique of removing the medial lacrimal wall and mucosa flush with the borders of each other has given $100 \%$ surgical success in treating the obstruction.

\section{Conclusion}

Endonasal dacryocystorhinostomy has become the preferred surgery for the treatment of nasolacrimal duct obstruction. In an attempt to make the surgery easier and simpler, we describe a new technique of endonasal DCR which has given excellent result, less costly and is simple enough to perform even in rural setting. This new technique gives $100 \%$ success and it is open for evaluation with higher number of cases.

\section{Acknowledgements}

We would like to express our gratitude and thankfulness to our ophthalmologist colleagues, anaesthetists and the whole staff of ENT department for their support, hard work and dedication.

\section{References}

[1]. Caldwell GW. Two new operations for obstruction of the nasal duct with preservation of the canaliculi, and anincidental description of a new lacrimal probe. New YorkMedical Journal. 1893; 57: 581-2.

[2]. Toti A. Nuovo metodo conservatore dicuraradicale delle sopourazioni croniche del saccolacrimale (dacriocistorhinostomia). Clin Moderna 1904; 10:385-87.

[3]. G Adrien Shun-Shin Geetha Thurairajan. External dacryocystorhinostomy - an end of an era?. British Journal of Ophthalmology 1997;81:716-17.McDonough M, Meiring JH. Endoscopic transnasal DCR. The journal of Laryngology and Otology. 1989; 103: 585-7

[4]. Fayers T, Laverde T, Tay E, Olver JM. Lacrimal surgery success after external dacryocystorhinostomy: functional and anatomical results using strict outcome criteria. Ophthal Plast Reconstr Surg. 2009 Nov-Dec;25(6):472-5.

[5]. Acharya K, Pradhan B, Thapa N, Khanal S. Comparision of outcome following endoscopic dacryocystorhinostomy with external Dacryocystorhinostomy. Nepalese journal of ENT head and neck Surgery, 2011:2(2):2-3.

[6]. Saroj Gupta, Rashmi Goyal, A.S.Thakur, Harpal Singh. Conventional Dacryocystorhinostomy Versus Endonasal Dacryocystorhinostomy -A Comparative Study. People's Journal of Scientific Research 2008 ; 1: 1-4.

[7]. Tsirbas A, Davis G, Wormald PJ. Mechanical endonasal dacryocystorhinostomy versus external dacryocystorhinostomy. Ophthal Plast Reconstr Surg. 2004 Jan;20(1):50-6.

[8]. Tsirbas A, Wormald PJ. Endonasal dacryocystorhinostomy with mucosal flaps. Am J Ophthalmol. 2003 Jan;135(1):76-83.

[9]. Renato RoithmannI; Tiana BurmanII; Peter-John Wormald. Endoscopic dacryocystorhinostomy. Braz. j. otorhinolaryngol. 2012;78(6):113-21.

[10]. Tsirbas A, Wormald P. Agger nasi cell mucosal autograft for lacrimal sac reconstruction during endonasal dacryocystorhinostomy. Orbit. 2004 Jun;23(2):105-10.

[11]. Tsirbas A, Wormald PJ. Mechanical endonasal dacryocystorhinostomy with mucosal flaps. Br J Ophthalmol. 2003 Jan;87(1):43-7.

[12]. Codère F, Denton P, Corona J. Endonasal dacryocystorhinostomy: a modified technique with preservation of the nasal and lacrimal mucosa. Ophthal Plast Reconstr Surg. 2010 May-Jun;26(3):161-4.

[13]. Dong Wook Kim, MD , Mi-Young Choi, MD, Woo Sub Shim. Endoscopic dacryocystorhinostomy with canalicular marsupialization in common canalicular obstruction. Canadian Journal of Ophthalmology, Aug 2013; 48(4): 335-39.

[14]. Callejas CA, Tewfik MA, Wormald PJ. Powered endoscopic dacryocystorhinostomy with selective stenting. Laryngoscope. 2010 Jul;120(7):1449-52.

[15]. Fayet B , Racy E, Assouline M. Complications of standardized endonasal dacryocystorhinostomy with unciformectomy. Ophthalmology. 2004 Apr;111(4):837-45.

[16]. Amit Pal Singh1, Vineet Narula2, Ravi Meher. A new approach to endoscopic DCR. Braz J Otorhinolaryngol. $2012 ; 78(5): 7-11$.

[17]. Ji QS , Zhong JX, Tu YH, Wu WC. New mucosal flap modification for endonasal endoscopic dacryocystorhinostomy in Asians. Int J Ophthalmol. 2012;5(6):704-7.

[18]. A.S. Harugop, B.K. Rekha, R.S. Mudhol, N.D. Zingade, S.M. Hugar, A.T Das et al. A randomized placebo controlled trial of Mitomycin C in in surgical outcome of primary endoscopic dacryocystorhinostomy. Al Ameen J Med Sci 2013; 6(3) :231-36. 
[19]. Mann BS , Wormald PJ. Endoscopic assessment of the dacryocystorhinostomy ostium after endoscopic surgery. Laryngoscope. $2006 \mathrm{Jul} ; 116(7): 1172-4$

[20]. Madge SN , Chan W, Malhotra R, Ghabrial R, Floreani S, Wormald PJ, Tsirbas A, Selva D. Endoscopic dacryocystorhinostomy in acute dacryocystitis: a multicenter case series. Orbit. 2011 Jan;30(1):1-6.

[21]. M K Tutton1 and N P O'Donnell. Endonasal laser dacryocystorhinostomy under direct vision. Eye (1 995) 9, 485-87.

[22]. Khawaja Khalid Shoaib, Salahuddin Ahmad, Muhammad Manzoor, Sabihuddin Ahmed, Iftikhar Aslam, Syed Nadeem ul Haq. Problems / Complications, Success Rate - Endoscopic Dacryocystorhinostomy. Pak J Ophthalmol 2012;28 (1): 17-21. 